\title{
Correction to: Aptamer-Based Approach as Potential Tools for Construction the Electrochemical Aptasensor
}

\author{
Rezvan Mansouri ${ }^{1} \cdot$ Azadeh Azadbakht $^{1}$
}

Published online: 28 November 2018

○) Springer Science+Business Media, LLC, part of Springer Nature 2018

\section{Correction to: \\ Journal of Inorganic and Organometallic Polymers and Materials \\ https://doi.org/10.1007/s10904-018-1024-3}

The original version of this article unfortunately contained a mistake. The author named Azadeh Azadbakht was listed twice in the publication.

The original article has been corrected.

The original article can be found online at https://doi.org/10.1007/ s10904-018-1024-3.

Azadeh Azadbakht

Azadbakht.a@gmail.com

1 Department of Chemistry, Khorramabad Branch, Islamic

Azad University, Khorramabad, Iran 